\title{
Bacterial Isolates and Antibiotic Sensitivity Pattern from Urinary Tract Infection in a Private Diagnostic Laboratory in Dhaka, Bangladesh
}

\author{
Md. Habibur Rahman ${ }^{1 *}$, Md. Mushtaque Ahmed ${ }^{2}$, Dayanidhi Sarkar' Md. Asadur Rahman ${ }^{4}$

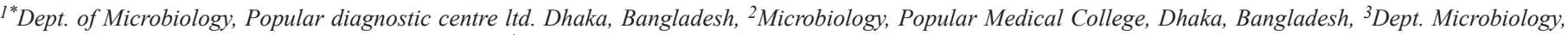 \\ Primeasia University, Banani, Dhaka, Bangladesh, ${ }^{4} \mathrm{Jr}$. Consultant, Dept. of Immunology, Popular diagnostic centre ltd. Dhaka, Bangladesh.
}

\begin{abstract}
Urinary tract infection (UTI) is a common infection encountered by clinicians and despite the widespread availability of antimicrobial agents, UTI has become difficult to treat because of appearance pathogens with increasing resistance to antimicrobial agents. The objectives of this study were to determine the pathogens causing UTI and to determine the antibiotic sensitivity status among these isolates in a diagnostic laboratory in Dhaka city. A laboratory based cross sectional survey was conducted in a diagnostic Centre in Dhaka Bangladesh from July 2016 to December 2016. A total of 553 urine samples were collected from each patients and processed in microbiology laboratory to isolate pathogens and antibiotic susceptibility test using standard procedure. Among 553 urine samples, 158 (28.57\%) samples was found to be culture positive of which $39(24.70 \%)$ were isolated from male patients and $119(\mathbf{7 5 . 3 0 \% )}$ from female patients. Escherichia coli $(\mathbf{4 3 . 6 7 \% )}$ were found to be the predominant pathogen followed by Staphylococcus spp. (16.45\%), Enterococcus spp. (13.39\%), Klebsiella spp. (13.29\%), Candida spp. (5.70\%), Acinetobacter spp. (4.43\%), Pseudomonas spp. (3.80\%) and Proteus spp. (1.27\%). The carbapenem group antibiotics (imipenem and meropenem) was found to be resistant in 0 to $5.1 \%$ of the Gram negative isolates. On the Other hand, most of the Gram positive isolates showed sensitivity to linezolid and vancomycin. This study showed that $E$. coli isolates were the predominant pathogens and showed resistance to commonly prescribed drugs resulting in a very few options for drug to treat UTIs.
\end{abstract}

Keywords: Urinary tract infection (UTI), Uropathogens, Antimicrobial susceptibility, Antimicrobial agents.

\section{Introduction}

Urinary tract infection (UTI) is the common bacterial infectious disease in community practice with high rate of morbidity and financial cost all over the world. About 150 million people are suffering from UTI each year Worldwide, costing 6 billion US dollars ${ }^{1}$. Nearly about $10 \%$ of people will experience UTI during lifetime ${ }^{2}$. UTIs refer to the presence of microbial pathogens within the urinary tract and it is usually classified by the site of infection of urinary bladder (cystitis), kidney (pyelonephritis) or urine (bacteriuria). Almost $95 \%$ of cases of UTI are caused by bacteria that typically multiply at the opening of the urethra and travel up to the bladder.

A limited predictable spectrum of organism is responsible for urinary tract infection. Most of the UTI are caused by Gram negative bacteria like E. coli, Klebsiella spp., Pseudomonas aeruginosa, Proteus spp., Acinetobacter spp. Serratia and Morganella margani. UTI can be caused by Gram positive bacteria too. Presence of Enterococcus spp., Staphylococcus especially coagulase negative Staphylococci and Streptococcus agalactiae were also reported ${ }^{3}$. UTI is much more common in women than in men due to anatomical and physiological reason; by virtue of its position, urogenital tract is more vulnerable to bacterial infection caused by internal and external flora.

Studies from India, Navaneeth et al., Bangladesh, Iqbal et al., and Nepal, Srinivassa et al. have reported an increased resistance of the urinary pathogens to commonly used antibiotics ${ }^{4-6}$. The aim of this study was to determine microbial etiologic agents responsible for urinary tract infection and to evaluate their in vitro susceptibility pattern to commonly used antimicrobial agents in a private practice set up of Dhaka city. This study is important for clinicians in order to facilitate the effective treatment and management of patients with symptoms of urinary tract infection.

\section{Materials and Methods}

Study design: A prospective cross-sectional study was conducted in the dept. of Microbiology, Popular diagnostic centre ltd. Dhaka, Bangladesh. A total of 553 samples were collected during this study period from July 2016-Dec 2016. 


\section{Inclusion/Exclusion criteria}

Study population consisted of all the patients who visited the concerned laboratory for urine culture examination.

\section{Sample collection and processing}

Study population were instructed on how to collect clean-catch mid-stream urine. Freshly voided midstream urine $(10-20 \mathrm{ml})$ from each patient was collected in a wide mouth sterile container supplied by the laboratory and bring to the laboratory as early as possible, usually within 1 hour after collection ${ }^{7}$.

\section{Microscopy}

The urine samples were mixed thoroughly, centrifuged and examined microscopically for wet mount preparation.

\section{Culture}

A calibrated sterile Nicrome wire loop for the semi-quantitative method was used for the plating. It has a $4 \mathrm{~mm}$ diameter loop to deliver $0.01 \mathrm{ml}$ of liquid. A loopful of the well mixed urine sample was inoculated on Hi-Chrome (Himedia, India), MacConkey and Blood agar media (Mast diagnostic, UK) and then incubated at $37^{\circ} \mathrm{C}$ aerobically for $24 \mathrm{hrs}$ and for $48 \mathrm{hrs}$ in negative cases. They were then screened for bacterial growth. A significant bacterial count was considered as any count equal to or in excess of $100,000 \mathrm{CFU} / \mathrm{ml}$. A less than $100 \mathrm{CFU} / \mathrm{ml}$ was interpreted as negative. Bacterial identifications were carried out based on standard culture and biochemical characteristics of isolates.

\section{Antibiotic susceptibility testing}

In the present study, antimicrobial susceptibility testing was done on Mueller-Hinton agar media (Mast diagnostic, UK) using disk diffusion (Kirby Bauer's) method according to the Clinical Laboratory Standard Institute (CLSI) guidelines using the following antimicrobial agents: Ampicillin 10 $\mu \mathrm{g}$, Amikacin $30 \mu \mathrm{g}$, Aztreonam 30 $\mathrm{g}$, Cefepime $30 \mu \mathrm{g}$, Ceftriaxone $30 \mu \mathrm{g}$, Ceftazidime $30 \mu \mathrm{g}$ Cefixime $5 \mu \mathrm{g}$, Cefoxitin $30 \mu \mathrm{g}$, Cloxacillin $5 \mu \mathrm{g}$ Cotrimoxazole $25 \mu \mathrm{g}$, Ciprofloxacin $5 \mu \mathrm{g}$, Imipenem $10 \mu \mathrm{g}$, Gentamicin $10 \mu \mathrm{g}$, Meropenem $10 \mu \mathrm{g}$, Netilmicin $30 \mu \mathrm{g}$, Nitrofutantion $300 \mu \mathrm{g}$, Levofloxacin $5 \mu \mathrm{g}$ Vancomycin $30 \mu \mathrm{g}$, Linezolid $30 \mu \mathrm{g}$, Netilmicin $30 \mu \mathrm{g}$, Penicillin $10 \mu \mathrm{g}$. Reference strains of E. coli ATCC 25922 and S. aureus ATCC 25923 were used for quality control for antimicrobial susceptibility tests $^{8}$.

\section{Statistical analysis}

The statistical analysis of data was performed using Microsoft Excel-2011 version. Discrete values were expressed as percentage. Descriptive statistics were used to summarize patient characteristics and the prevalence of antimicrobial sensitivity.

\section{Results}

Out of 553 urine samples, only 158 (28.57\%) was found to be culture positive, having a bacterial load of e" $10^{5} \mathrm{cfu} / \mathrm{ml}$. Of 158 culture positive samples, 39 (24.70\%) were from male patients and $119(75.30 \%)$ from female patients and other $395(71.43 \%)$ sample were negative or normal flora.

Table 1. Growth of Urine culture among the study population $(n=553)$

\begin{tabular}{lccc}
\hline Culture & Frequency (\%) & Male (\%) & Female (\%) \\
\hline Positive & $158(28.57)$ & $39(24.68)$ & $119(75.32)$ \\
Negative & $395(71.43)$ & $155(39.00)$ & $241(61.00)$ \\
\hline Total & $553(100)$ & $194(35.00)$ & $360(65.00)$ \\
\hline
\end{tabular}

Most of the patients were in age group of 21 to 40 years, of which $38(17.92 \%)$ cases were positive. In this age group, $34(98.12 \%)$ were female and $4(1.88 \%)$ were male. In the age group of less than 20 years, number of female patients was also higher than male patient which is $16(61.54 \%)$ and $10(38.46 \%)$ cases respectively. Overall, female cases were more common than male, shown in Table 2.

Table 2. Age and sex distribution of culture positive patient $(n=158)$

\begin{tabular}{lcccc}
\hline Age & No & Growth $(\%)$ & Female (\%) & Male (\%) \\
\hline$<20$ & 105 & $26(24.76)$ & $16(61.54)$ & $10(38.46)$ \\
$21-40$ & 212 & $38(17.92)$ & $34(98.12)$ & $4(1.88)$ \\
$41-60$ & 152 & $60(39.47)$ & $48(80.00)$ & $12(20.00)$ \\
$61-80$ & 77 & $29(37.66)$ & $19(65.52)$ & $10(34.48)$ \\
$>80$ & 7 & $5(71.42)$ & $2(40.00)$ & $3(60.00)$ \\
\hline
\end{tabular}

The most common isolates in this study was found to be Gram negative bacilli which accounts for $66.45 \%$ of the total isolates. Of the Gram negative bacilli, the predominant isolate was the $E$. coli $(43.96 \%)$ followed by other bacilli like Klebsiella spp. (13.29\%), Acinetobacter spp. (4.43\%), Pseudomonas spp. (3.80\%) and Proteus spp. (1.27\%) among the major isolates. The most prominent Gram positive bacteria identified was Staphylococcus spp., accounts for $16.45 \%$ of total isolates, followed by Enterococcus spp. (13.39\%). Candida spp. was responsible for $(5.70 \%)$ of cases. Table 3 shows the detailed frequency of all the isolates. 
Table 3. Frequency of positive isolates with based on sex.

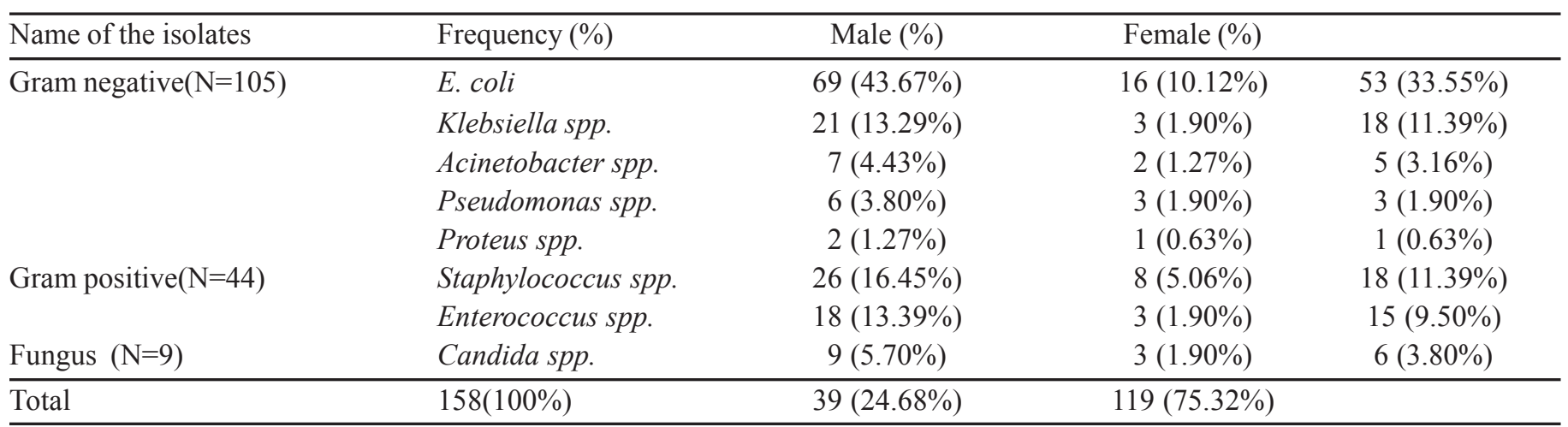

Table 4. Distribution of Antibiotic sensitivity among the bacterial isolates

\begin{tabular}{|c|c|c|c|c|c|c|c|}
\hline \multirow[t]{2}{*}{ AntibioticSusceptibility } & \multicolumn{5}{|c|}{ Gram negative isolates } & \multicolumn{2}{|c|}{ Gram positive isolates } \\
\hline & $\begin{array}{c}\text { E. coli } \\
n=69(\%)\end{array}$ & $\begin{array}{c}\text { Klebsiella } \\
n=21(\%)\end{array}$ & $\begin{array}{c}\text { Acinetobacter } \\
n=7(\%)\end{array}$ & $\begin{array}{c}\text { Pseudomonas } \\
n=6(\%)\end{array}$ & $\begin{array}{l}\text { Proteus } \\
n=2(\%)\end{array}$ & $\begin{array}{c}\text { Staphylococcus } \\
\mathrm{n}=26(\%)\end{array}$ & $\begin{array}{c}\text { Enterococcus } \\
\mathrm{n}=18(\%)\end{array}$ \\
\hline Ampicillin & $3(4.34)$ & $3(14.28)$ & $0(0.00)$ & $0(0.00)$ & $0(0.00)$ & $2(7.69)$ & $16(88.88)$ \\
\hline Cephradine & $6(8.69)$ & $5(23.80)$ & $0(0.00)$ & $0(0.00)$ & $1(50.00)$ & - & - \\
\hline Cefriaxone & $21(30.43)$ & $14(66.66)$ & $2(28.57)$ & $2(33.33)$ & $1(50.00)$ & - & - \\
\hline Cefixime & $20(28.98)$ & $12(57.14)$ & $1(14.28)$ & $0(0.00)$ & $1(50.00)$ & - & - \\
\hline Ceftazidime & $43(62.31)$ & $15(71.42)$ & $3(42.85)$ & $3(50.00)$ & $2(100.0)$ & - & - \\
\hline Cefepime & $47(68.11)$ & $16(76.19)$ & $4(57.14)$ & $4(66.66)$ & $2(100.0)$ & - & - \\
\hline Imipenem, & $65(94.20)$ & $20(95.23)$ & $6(85.71)$ & $5(83.33)$ & $2(100.0)$ & $25(96.15)$ & $16(88.88)$ \\
\hline Meropenem & $65(94.20)$ & $20(95.23)$ & $6(85.71)$ & $5(83.33)$ & $2(100.0)$ & $25(96.15)$ & $16(88.88)$ \\
\hline Cotrimoxazole & $26(37.63)$ & $10(47.61)$ & $1(14.28)$ & $0(0.00)$ & $1(50.00)$ & $12(46.15)$ & - \\
\hline Gentamycin & $53(76.81)$ & $16(76.19)$ & $5(71.42)$ & $4(66.66)$ & $2(100.0)$ & $22(84.61)$ & - \\
\hline Netilmicin & $58(84.05)$ & $17(80.95)$ & $5(71.42)$ & $5(83.33)$ & $2(100.0)$ & $23(88.46)$ & - \\
\hline Amikacin & $62(89.85)$ & $19(90.47)$ & $6(85.71)$ & $5(83.33)$ & $2(100.0)$ & $24(92.30)$ & - \\
\hline Ciprofloxacin & $27(39.13)$ & $12(57.14)$ & $2(28.57)$ & $2(33.33)$ & $1(50.00)$ & $11(42.30)$ & $12(66.66)$ \\
\hline Levofloxacin & $30(43.47)$ & $12(57.14)$ & $2(28.57)$ & $2(33.33)$ & $1(50.00)$ & $12(46.15)$ & $12(66.66)$ \\
\hline Doxycycline & $13(18.84)$ & $8(38.09)$ & $0(0.00)$ & $0(0.00)$ & $0(0.00)$ & $9(34.61)$ & $13(72.22)$ \\
\hline Tertracycline & $13(18.84)$ & $8(38.09)$ & $0(0.00)$ & $0(0.00)$ & $0(0.00)$ & $9(34.61)$ & $13(72.22)$ \\
\hline Nitrofurantoin & $61(88.40)$ & $13(61.90)$ & $6(85.71)$ & $4(66.66)$ & $2(100.0)$ & $22(84.61)$ & $16(88.88)$ \\
\hline Aztreonam & $36(52.17)$ & $13(61.90)$ & $4(57.14)$ & $3(50.00)$ & $2(100.0)$ & - & - \\
\hline Cefoxitin & $53(76.81)$ & 17(76.19) & $5(71.42)$ & $4(66.66)$ & $2(100.0)$ & $18(69.23)$ & - \\
\hline Cloxacillin & - & - & - & - & - & $18(69.23)$ & - \\
\hline Tigecycline & - & - & - & - & - & $26(100.0)$ & $18(100.0)$ \\
\hline Lenizolid & - & - & - & - & - & $26(100.0)$ & $18(100.0)$ \\
\hline Vancomycin & - & - & - & - & - & $24(92.30)$ & $16(88.88)$ \\
\hline
\end{tabular}

\section{Discussion}

This study provides valuable data to isolate and to identify the pathogen which cause urinary tract infection and monitor the status of antimicrobial sensitivity among uropathogens to improve efficient empirical treatment. In addition to that the susceptibility pattern of these bacteria is very important to avoid development of drug resistant ${ }^{9}$. In our study isolation and identification of uropathogens were performed and 158(28.57\%) urine sample showed significant growth of bacteria so, remaining majority 395
$(71.43 \%)$ of the cases showed either insignificant bacteriuria or no growth with urine from the suspected cases of UTI.

This study resembles to the study conducted by Yusuf et al., $2015^{10}$ and Barber et al., $2013^{11}$ and they showed $28 \%$ significant bacterial growth.

The reason of low growth rate may be due to irrational use of antibiotic which is available in the local market in this country and these are given without prior culture and antibiotic sensitivity pattern. In addition to that, incomplete doses are another factor. 
Prior antibiotic therapy before sending urine sample for culture and sensitivity and other clinical conditions like non-gonococcal urethritis could be the factors responsible for insignificant bacteriuria or no growth ${ }^{11}$.

In this study showed the prevalence was high in females than males for each isolates $75.31 \%$ and $24.68 \%$ respectively, so we can say strictly female suffers more than male from UTI. Other studies also showed that urinary tract infection was more common in females. Akhter et al., $2012^{12}$ and Yusuf et al., $2015^{10}$ was found $71.6 \%$ and $66.6 \%$ respectively. It is well established that female are more commonly infected with UTI than male due to anatomical position of urethra, influence of hormone and pregnancy ${ }^{13}$. The international studies have shown that UTIs in women are very common; therefore, one in five adult women experience UTI in her life and it is extremely common, clinically apparent, worldwide patient problem.

The most frequently isolated bacteria in this study was $E$. coli (43.67\%) followed by Staphylococcus spp. (16.45\%), Enterococcus spp. (13.39\%), Klebsiella spp. (13.29\%), Acinetobacter spp. (4.43\%), Candida pp. (5.70\%), Psudomonas spp. (3.80\%) and Proteus spp. (1\%.27). These results correlated with the study by Rana et al. ${ }^{14}$ who found the predominance of E. coli (46.66\%) followed by Staphylococcus spp. (15.8\%), and also with Shaaban et al. ${ }^{15}$, who also found that $E$. coli is most prevalent isolates in urine accounting up to $43 \%$, followed by klebsiella pneumonieae (14.1\%), Pseudomonas aeruginosa and Proteus mirabilis (9.4\%).

Predominance of $E$. coli among the different uropathogens, was also found by Oluremi et al. ${ }^{16}$ and by Chakupurakal et al. ${ }^{17}$. The dominance of E. coli is followed by Staphylococcus spp. $(16.45 \%)$ in this study resembles to the study done by Jha and Bapat, ${ }^{18}$ which was the second most organisms causing UTI.

Antibiotic susceptibility test reveals that higher percentage of susceptibility for Imipenem and Meropenem, which accounts for $96 \%$ of the cases, followed by Nitrofurantoin ( $88 \%$ ), Amikacin $(88 \%)$, Netilmicin (88\%), shown in table-4. This study resembles to the study conducted by Farjana et al. ${ }^{19}$ where higher percentage of susceptibility was seen for Amikacin (88\%). Second is the Nitrofurantoin which considered as an appropriate agent for first line treatment of community acquired UTIs.

Ampicillin was found to show the higher resistance rate (98\%) which resembles to the study conducted by Nerukar et al. ${ }^{20}$ which showed that isolates of most of the species exhibited a high rate of resistance to ampicillin. Resistance to antibiotics develops due to its frequent misuse ${ }^{21}$.

According to the above results, among antibiotics used for susceptibility test for Gram negative bacteria, Amikacin, Netilmicin and Nitrofurantoin was found to be the most effective antibiotics followed by Gentamicin, Cefoxitin, Cefepime and Ceftazidime for the isolates respectively were sensitive.
In present study, E. coli and Klebsiella showed maximum sensitivity to nitrofurantoin. Almost all Gram negative isolates are least sensitive to Cephlosporin and fouroquinolones groups. Pseudomonas spp. was found to resistant against all commonly used antibiotic and sensitive to Imepenem, Meropenem. The higher rate of resistance might be a result of the irrational use of antibiotics $^{21}$.

Staphylococcus spp. and Enterococcus spp. was found to be sensitive to Linezolid (100\%), Vancomycin (94\%). This is comparable with study of Jayshri et al. ${ }^{21}$. The antimicrobial susceptibility pattern confirms that most of the urinary isolates in our environment are resistant to the commonly used antibiotic including the cephalosporin and fluoroquinolones. In particular, the high resistance of the gram negative isolates to the fluoroquinolones is worrisome as these are reserve drugs for treating resistance infections ${ }^{22}$.

\section{Conclusion}

A drug resistance among bacterial pathogen is an evolving process, regular surveillance and monitoring is necessary to provide physicians knowledge on the updated and most effective empirical treatment of UTIs. Periodic reassessment of in vitro susceptibility pattern of urinary pathogens to serve as a guide for antibiotic therapy since these organism exhibit resistances to firstline drugs used for UTI. In order to prevent decrease resistance to antibiotics, the use of antibiotics should be kept under supervision, should be given in appropriate doses for an appropriate period of time.

In the present study, community-acquired UTI and nosocomial UTI were not been distinguished. This was the main limitation of the study.

\section{Acknowledgements}

Authors are very much thankful to honorable Dr. Mostafizur Rahman, Managing Director and CEO, Popular Diagnostic Centre Ltd., Dhaka-1205 and Md. Shahi Mahmud, Branch Manager, Popular Diagnostic Centre Ltd., Shantinagar, Dhaka-1217 for providing necessary facilities and support.

\section{References}

1. Gonzalez CM, Schaeffer AJ.1999. Treatment of urinary tract infection: what's old, what's new, and what works. World journal of Urology. 7: 372-382.

2. Hoberman A, Wald ER.1997. Urinary tract in young febrile children. $J$. Pediatr infect dis. 16: 11-17.

3. Mohamed Shaaban T, Hassan Ghozlan A, Marwa Maghraby ME. 2012. Susceptibility of bacteria infecting urinary tract to some antibiotics and Essential oils. J. Clin. Microbiol. and Infect. Dis. 18: 153-166.

4. Navaneeth BV, Belwadi S, Suganthi N. 2002. Urinary pathogrns, resistance to common antibiotics: a retrospective analysis. Trop Doct. 32: 20-22.

5. Iqbal J, Rahman M, Kabir MS, Rahman M. 1997. Increasing ciprofloxacin resistance among prevalent urinary tract bacterial isolates in Bangladesh. Jpn J Med Sci Biol. 50: 241-250.

6. Srinivassa H, Parija SC, Bhattacharya S, Sehgal R. 1999. Incidence of ciprofloxacin resistance in urinary isolates. Estern Nepal J Comm Dis. 31: $45-47$. 
7. Collee, J. G., Duguid, J. P., Fraser, A. G. and Marmion, B. P. 1996. In. Laboratory strategies in the diagnosis of infectious syndromes. in Practical Medical Microbiology, eds Collee, J. G., Barrie, M. P., Fraser, A.G. and Simons, A. $14^{\text {th }}$ ed. Churchill Livingstone, New York, 53-93.

8. Clinical and Laboratory Standard Institute: Performance standard for antimicrobial susceptibility testing; seventeeth information supplement. CLSI document M100 S17, Clinical and Laboratory Standard Institute Waynne Pennsylvania. 2014)

9. Behzadi P, Behzadi E, Yazdanbod H, Aghapour R, Cheshmeh MA, Omran DS. 2010. A survey on urinary tract infections associated with the three most common uropathogenic bacteria. Maedica. 5(2):111-115.

10. Md. Abdullah Yusuf, Afroza Begum and Chowdhury Rafiqul Ahsan 2015. Anibiotic sensitivity pattern of Gram negative uropathogenic bacilli at a private hospital in Dhaka city. Al Ameen J Med Sci. 8(3): 189-194.

11. Barber AE, Norton JP, Spivak AM, Mulvey MA. 2013. Urinary Tract Infections: Current and Emerging Management Strategies. Clin Infect Dis. 57(12): doi: 10.1093/cid/cit284

12. Akhter S and Kabir MH. 2016. Bacterial Isolates and Drug susceptibility Patterns of Urinary tract Infection at Shaheed Monsur Ali Medical College. Austin J Microbiol. 2(1): 2471-0296.

13. Jones R N, Kugler K C, Pfaller M A, and Winokur P L. 1999. Characteristics of pathogens causing Urinary Tract Infections in hospitals in North America, Results from the Sentry Antimicrobial Survillance Program, 1997., Diagn Microbiol Infect Dis. 35: 55-63.

14. Rana M A A, Sawsan M A, Khabat AA, Wesam AB. (2014). Antibacterial activity of parsley and cerery aqueous extract on the isolated bacteria from children UTI in Erbil city.
15. Shaaban MT, Ghozlan HA, and EI Maghraby MM. 2012. Susceptibility of Bacteria Infecting Urinary Tract of Some Antibiotics and Essential Oils. J. Appl Pharma. Sci. 02(04): 90-98.

16. Oluremi BB, Idowu AO, Olaniyi JF. 2011 Antibiotic susceptibility of common bacterial pathogens in urinary tract infection in a teaching hospital in southwestern Nigeria. Afr J Microbiol Res. 5: 3658-3663.

17. Chakupurakal R, Ahmed M, Sobithadevi DN, Chinnappan S, Reynolds T. 2010. Urinary tract Pathogens and Resistance Pattern. J Clin Pathol. 63: $652-654$

18. Jha N, and Bapat S K. 2005. A study of sensitivity and resistance of pathogenic microorganisms causing UTI in Kathmandu valley. Kathmandu Univ Med J. 3(2): 123-129.

19. Farjania S. Alikhani MY. Ghotaslou R. Naghili B. Nakhlband A. Causative agents and Antimicrobial sustebtibility of UTIs in the nirthwest of Iran safar. Int. J. infect. Dis. 13: 140-144

20. Nerukar A, Solanky P, Naik SS. 2012. Bacterial pathogens in UTI and antibiotic susceptibility pattern. J. pharm. Biomed. Sci. 21: 1-3

21. Dr. Jayshri V Dund, Dr. Rakesh Ninama, Dr. Mala Sinha. 2015. Antibiotic sensitivity pattern of bacteria isolated from catheter associated UTI in a tertiary care hospital, Jamalnagar Sch. J. App. Med. Sci. 3(5C): 19851988

22. Aderounmu T. 2006. Catheter Associated Urinary Tract Infection: Aetiologic agent and antimicrobial susceptibility pattern in LadokeAkintola University teaching hospital, Osogbo, Nigeria. African J. Biomed. Res. 9:141-148. 